\title{
EVOLUÇÃO DA AGROINDÚSTRIA CANAVIEIRA NO BRASIL (1990-2014): DA RUPTURA DO PARADIGMA SUBVENCIONISTA À FALTA DE PLANEJAMENTO
}

\section{EVOLUTION OF CANAVIEIRA AGROINDÚSTRIA IN BRAZIL (1990-2014): FROM THE RUPTURE OF THE SUBVENTIONAL PARADIGM TO THE LACK OF PLANNING}

\author{
Pery Francisco Assis Shikida \\ Universidade Estadual do Oeste do Paraná, Cascavel, PR, Brasil. \\ E-mail: pery.shikida@unioeste.br \\ Darcy Jacob Rissardi Júnior \\ Universidade Tecnológica Federal do Paraná, Curitiba, PR, Brasil \\ E-mail:darcy@utfpr.edu.br
}

Recebido em 12.01.2017 - Aceito em: 05.03.2017

\section{RESUMO}

Este artigo busca analisar, de forma concisa e numa perspectiva histórica, a evolução da agroindústria canavieira pós-desregulamentação (1990-2014). Os resultados mostram três fases distintas. Na primeira fase, 1986/1987 a 1995/1996, houve desaceleração e crise do Proálcool e ruptura do paradigma subvencionista. Na segunda fase, 1996/1997 a 2002/2003, houve recrudescimento da desregulamentação, explicitação da debilidade estrutural e o surgimento da diversidade de interesses. Finalmente, a terceira fase, 2003/2004 a 2013/2014, houve a retomada do etanol com o mercado flex-fuel, muitos Investimentos Diretos Estrangeiros (IDE) e falta de planejamento por parte do governo federal na condução da política de precificação da gasolina, que desestimulou o consumo de etanol.

PALAVRAS-CHAVE: Cana-de-açúcar, perspectiva histórica, fases.

\section{ABSTRACT}

This article seeks to analyze concisely and historically the evolution of sugarcane agroindustry post-deregulation (1990-2014). The results show three distinct phases. In the first phase, 1986/1987 to 1995/1996, there was the slowdown and crisis of Proalcool Program and break down of subsidizing paradigm. The second phase, 1996/1997 to 2002/2003, there was an increasing of deregulation, showing the structural weakness and the emerging of a variety of interests. Finally, the third phase, 2003/2004 to 2013/2014, there was the resumption of ethanol with flex-fuel market, loads of Foreign Direct Investments (FDI) and lack of planning from the Federal government in the market of gasoline price, that discourage the ethanol use.

KEYWORDS: Sugarcane, historical perspective, phases. 


\section{1. "DESACELERAÇÃO E CRISE DO PROÁLCOOL E RUPTURA DO PARADIG- MA SUBVENCIONISTA (1986/1987 A 1995/1996)"}

Este artigo tem como objetivo analisar, de forma concisa, a evolução da agroindústria canavieira no Brasil pós-desregulamentação (1990-2014) à guisa da literatura e sob o enfoque de três fases características: "desaceleração e crise do Proálcool e ruptura do paradigma subvencionista (1986/1987 a 1995/1996)"; "recrudescimento da desregulamentação, explicitação da debilidade estrutural e o surgimento da diversidade de interesses na agroindústria canavieira (1996/1997 a 2002/2003)"; "retomada do etanol com o mercado flex-fuel, IDE e falta de planejamento (2003/2004 a 2013/2014)" . Esta perspectiva histórica, baseada em referências da área e numa periodização concatenada, é o norte metodológico do artigo.

Embora este trabalho verse especificamente sobre a evolução da agroindústria canavieira no Brasil pós-desregulamentação (1990-2014), o entendimento do período supracitado requer um breve entendimento predecessor. Neste sentido, qual era o contexto nacional e mundial em que se deparava a agroindústria canavieira no País na década que antecedeu o período pós-desregulamentação setorial de 1990? Responder a esta pergunta contribui para entender os acontecimentos que marcaram a desaceleração e crise do Programa Nacional do Álcool (Proálcool) e a consequente ruptura do paradigma subvencionista.

Para alguns estudiosos da economia brasileira, como Carneiro e Modiano (1992) e Bacha (2007), os anos 1980 são considerados "anos difíceis", consubstanciados, por exemplo, na reduzida taxa média de crescimento anual do Produto Interno Bruto (PIB) de 3\%, resultado da ruptura no processo de crescimento da economia brasileira que, desde o pós-guerra (1946) até 1979, vinha apresentando taxas médias de crescimentos anuais acima de 7\%. Com o esgotamento desse modelo, a economia passou a conviver com um cenário adverso, marcado por crises conjunturais de enorme impacto não só para o Brasil como também para a economia mundial (como as crises do petróleo de 1979 e o súbito e substancial aumento dos juros internacionais no início dos anos 1980), devido ao elevado endividamento interno e consequente crise fiscal, e aceleração inflacionária jamais vista na história brasileira. Para Barros e Moraes (2002), nessa fase, ainda, deve ser realçada a transição de um regime com fortes características autoritárias e burocráticas para um sistema com características mais democráticas.

Com efeito, a economia brasileira, ao longo da segunda metade dos anos 1980 e início dos anos 1990, foi marcada fundamentalmente pela conjuntura de crise fiscal do Estado e descontrole da inflação, em ambiente de redemocratiza- 
ção, com um cenário externo desfavorável. Nesse período, que compreende a primeira delimitação temporal deste estudo, foram adotados alguns planos de estabilização econômica, quais sejam: Planos Cruzado I (1986) e Cruzado II (1986), Bresser (1987), Verão (1989), Collor I (1990) e Collor II (1991), que malograram na intenção de debelar a inflação. Somente com a implementação do Plano Real (1994) é que a inflação foi contida. As características marcantes do Plano Real foram: a desindexação da economia, com lançamento de uma nova moeda que vigora até hoje, o Real; a priorização do saneamento no setor público e privatização de algumas estatais; a ancoragem monetária e cambial; a abertura comercial, tecnológica e financeira (LACERDA et al., 2000; BACHA, 2007).

Dessa forma, não há como dissociar a evolução da agroindústria canavieira dos momentos de adoção de Planos de combate à inflação malsucedidos e de um Plano que logrou sucesso, e que trouxe um processo de reestruturação seguido de uma tendência de liberalização econômica. Esta conjuntura certamente comprometeu a política subvencionista outrora existente na agroindústria canavieira no Brasil, tanto que se constatou a retirada gradual da participação dos investimentos públicos no Proálcool entre 1985 e 1990, do qual 39\% foram oriundos de capital público e $61 \%$ de capital privado. Para cotejo, de 1975 a 1980, do total de investimentos no Proálcool, $25 \%$ dos recursos foram advindos do capital privado e $75 \%$ advindos do capital público. Ademais, o valor investido nesse Programa entre 1985 e 1990 também reduziu, sendo de US\$ 0,511 bilhão, enquanto que entre 1975 a 1980 foram investidos US\$1,02 bilhão (LOPES, 1996).

Para Goldin e Rezende (1993) e Dahmer-Felício (2011), a tônica de restruturação do Estado, experimentada no final dos anos 1980 e início dos anos 1990, muito caracterizada pela ideologia neoliberal, mas também afetada por uma séria crise fiscal que apontava para o fim dos incentivos e subsídios governamentais, aumento das privatizações, extinção e/ou fusão de várias instituições públicas, afetou toda a economia brasileira, e a economia canavieira não foi exceção, prova disso foi o tolhimento do investimento público no Proálcool, seja em termos absolutos ou relativos. Dahmer-Felício (2011, p.15) ainda aponta que, além dessas questões, no período de intervencionismo estatal na agroindústria canavieira era comum a ineficiência do Estado como planejador e regulador da atividade sucroalcooleira, "[...] os preços dos produtos frente aos custos de produção estavam defasados e o sistema de comercialização de álcool bem como a manutenção de estoques de segurança não atendiam às necessidades de mercado". Ou seja, "externamente" ao setor havia um contexto pró-políticas neoliberais, e "internamente" o próprio setor 
não estava funcionando adequadamente com as políticas intervencionistas.

Outro indicador de diminuição do ímpeto do Proálcool, carro chefe da agroindústria canavieira no Brasil nas fases de expansão moderada e acelerada desse Programa (1975/1976 a 1985/1986), pode ser observado por meio da taxa geométrica de crescimento média anual da produção canavieira, que caiu drasticamente para $0,92 \%$ a.a. (significativa a 5\%) em 1986/1987-1995/1996. Convém citar que, no período imediatamente anterior, esta taxa foi de $11,7 \%$ a.a. (significativa a $1 \%$ ). ${ }^{1}$

Considerando seus dois principais produtos, a taxa geométrica de crescimento média anual da produção de açúcar nessa fase foi de 5,7\% a.a. (significativa a 1\%), enquanto esta mesma taxa para a produção de etanol foi de 1,4\% a.a. (significativa a 5\%), revertendo uma tendência de importância dos dois principais produtos da agroindústria canavieira, antes voltada para o etanol. Cumpre citar, com base em dados da Agrianual (1996), que os preços internacionais do açúcar entre 1986 a 1996 foram, de certo modo, favoráveis à produção dessa commodity em função, sobretudo, da instabilidade das ofertas de açúcar da Índia, Tailândia e Cuba. Outro aspecto que deve ser ressaltado e que tem muita profusão na literatura (vide, por exemplo: MORAES e SHIKIDA, 2002; NARDY; GURGEL, 2013; MARTINS, 2015), é que tanto os preços do açúcar como do etanol são comumente ditados pelo mercado mundial, conforme condicionantes da produção, estoques e demandas dos diversos países que produzem tais commodities; muito embora alguns desses países adotem medidas protecionistas visando proteger suas produções domésticas. Destarte, mesmo o Brasil sendo um dos grandes players no mercado, não consegue ter controle sobre os preços do açúcar e/ou do etanol, sendo considerado um price taker.

Com base em dados da ALCOPAR (2015b), a taxa geométrica de crescimento média anual do consumo de álcool carburante entre os anos de $1986 \mathrm{e}$ 1996 foi de 2,1\% a.a. Em sendo a produção (1,4\% a.a.) menor do que o consumo, houve a necessidade de importação deste produto a partir de 1989 (PARRO, 1996). Neste ínterim, o Proálcool foi criado tendo como uma das finalidades a economia de divisas (via redução das importações de petróleo), mas se viu, naquele momento histórico, mudando sua perspectiva inicial. Como consequência, este descompasso entre consumo e oferta de etanol contribuiu fortemente para o descrédito dos consumidores de veículos movidos a etanol, favorecendo a preferência do consumidor para o veículo a gasolina, tanto que a percentagem de venda

1 A estimativa da taxa geométrica de crescimento está de acordo com o método dos mínimos quadrados. Ademais, utilizou-se também o teste " $\mathrm{t}$ " (em que se constrói um intervalo de confiança para observar se o valor alegado está ou não incluído nesse intervalo). Para maiores considerações sobre o processo de cálculo dessas taxas, ver: Hoffmann e Vieira (1987). 
EVOLUÇÃO DA AGROINDÚSTRIA CANAVIEIRA NO BRASIL (1990-2014):

DA RUPTURA DO PARADIGMA SUBVENCIONISTA À FALTA DE PLANEJAMENTO

de veículos a etanol no mercado interno nacional, que em 1987 foi de quase $90 \%$, apresentou redução até passar, em 1996, a somente 0,53\% desse total (Tabela 1).

Tabela 1 - Percentagem de venda de veículos a álcool no mercado brasileiro (1986-1996)

\begin{tabular}{c|c|c|c|c|c|c|c|c|c|c|c}
\hline Anos & $\mathbf{1 9 8 6}$ & $\mathbf{1 9 8 7}$ & $\mathbf{1 9 8 8}$ & $\mathbf{1 9 8 9}$ & $\mathbf{1 9 9 0}$ & $\mathbf{1 9 9 1}$ & $\mathbf{1 9 9 2}$ & $\mathbf{1 9 9 3}$ & $\mathbf{1 9 9 4}$ & $\mathbf{1 9 9 5}$ & $\mathbf{1 9 9 6}$ \\
\hline $\begin{array}{c}\text { \% de venda de veículos a álcool } \\
\text { no mercado interno }\end{array}$ & 88,64 & 89.3 & 83,33 & 56,75 & 12.4 & 21,19 & 27.89 & 26,1 & 11.75 & 3.05 & 0.53 \\
\hline
\end{tabular}

Fonte: ALCOPAR (2015c).

Esta desaceleração do Proálcool pode ser explicada pela ruptura do paradigma subvencionista que ocorreu na agroindústria canavieira e que Shikida (1997, p.159-161) tratou assim de explicar:

[...] da mesma forma que na primeira e segunda fase, onde o Proálcool obteve êxito com uma bem "orquestrada" junção de interesses, o seu malogro relativo deveu-se também a uma rápida desagregação desses interesses: seja no âmbito do Estado, agora revestido de uma tendência neoliberal e afetado por uma grave crise fiscal e financeira - que ainda mantém alguns privilégios da agroindústria canavieira, embora dê nítidos sinais de um gradual afastamento deste setor -; seja na deserção da indústria automobilística e/ou na falta de interesse do consumidor pelo carro a álcool, motivados pela diminuição das vantagens outrora concedidas para este tipo de veículo e diante das incertezas reinantes sobre o futuro do Proálcool; e, seja na própria agroindústria canavieira, capaz de redirecionar boa parte da produção canavieira para o mercado açucareiro ao menor sinal de elevação dos preços internacionais.

Diante do cenário de desaceleração do Proálcool, inserida numa conjuntura de crise fiscal do Estado brasileiro e descontrole da inflação, a extinção do IAA em 1990 marcou de vez a ruptura do paradigma subvencionista na agroindústria canavieira no Brasil, sendo que o presente estudo denomina de ponto de inflexão nessa nova institucionalidade setorial. Contudo, o afastamento do Estado do setor se deu de maneira gradual, é o que atesta Alves (2002) ao dizer que o preço do açúcar no mercado interno deixou de ser tabelado ainda no início da década de 1990, mas as exportações desse produto só foram liberadas a partir de 1994, e novas liberações ocorreriam mais adiante. Para Quadros (1995, p.22), "não há como dissociar o destino do Proálcool dos resultados do processo de reorganização do Estado".

Embora o IAA tenha sido extinto em 1990, o controle e planejamento da agroindústria canavieira se tornou responsabilidade da Secretaria de Desenvolvimento Regional da Presidência da República, de onde tais políticas foram orientadas durante essa fase. Posteriormente, visando alterar o sistema de tomadas de decisões e com o objetivo de analisar e propor políticas relativas ao segmento 
sucroalcooleiro, em 1997 foi criado o Conselho Interministerial do Açúcar e Álcool (CIMA) (MORAES, 2000).

Shikida (1997), Vian (2003) e Paulillo et al. (2007) ressaltam que, a partir da desregulamentação iniciada em 1990, os produtores e consumidores tiveram que se adaptar ao panorama mais próximo do livre mercado, com foco na redução dos custos de produção, por meio da adoção de inovações, melhoria da capacidade de produção de produtos e maior aproveitamento de subprodutos da agroindústria canavieira. Afinal, de uma vivência em que o intervencionismo estatal ditava praticamente todas as regras de mercado nessa atividade, "o papel do Estado mudou, ele agora é mais de coordenador do que interventor" (VIAN; 2003, p. 11). Não obstante, a desaceleração e crise do Proálcool e a ruptura do paradigma subvencionista contribuíram para avultar a diferenciação existente em termos produtivos na agroindústria canavieira do País, é o que evidencia a Tabela 2 a seguir.

Tabela 2 - Números índices relativos à produção de cana-de-açúcar em estados selecionados do Brasil, safras 1986/1987 a 1995/1996

\begin{tabular}{|c|c|c|c|c|c|c|c|c|c|c|}
\hline Estado & $86 / 87$ & $87 / 88$ & $88 / 89$ & $89 / 90$ & $90 / 91$ & $91 / 92$ & $92 / 93$ & $93 / 94$ & $94 / 95$ & $95 / 96$ \\
\hline São Paulo - SP & 50,2 & 56,0 & 57,0 & 55,4 & 59,7 & 60,2 & 61,5 & 66,2 & 62,2 & 60,7 \\
\hline Paraná-PR & 4,9 & 4,9 & 4,7 & 4,8 & 4,9 & 5,0 & 5,4 & 5,7 & 6,5 & 7,4 \\
\hline Mato Grosso do Sul -MS & 1,4 & 1,9 & 1,8 & 1,7 & 1,8 & 1,7 & 1,7 & 1,7 & 1,6 & 1,9 \\
\hline Mato Grosso-MT & 0,8 & 1,0 & 1,0 & 1,1 & 1,5 & 1,3 & 1,4 & 1,8 & 2,0 & 2,7 \\
\hline Goiás - GO & 2,1 & 2,3 & 2,0 & 1,8 & 1,9 & 2,0 & 2,2 & 2,3 & 2,4 & 2,5 \\
\hline Minas Gerais - MG & 4.6 & 5.2 & 4.6 & 4.2 & 4.5 & 4.6 & 3.9 & 3.9 & 4.0 & 3.6 \\
\hline Rio de Janeiro RJ & 3,8 & 3,5 & 1,1 & 3,3 & 2,0 & 2,9 & 2,3 & 2,2 & 2,3 & 2,1 \\
\hline Espirito Santo-ES & 0,9 & 1,0 & 0,9 & 0,8 & 0,5 & 0,8 & 0,8 & 0,6 & 0,8 & 0,7 \\
\hline Centro-Sul & 68.7 & 75.8 & 76.0 & 73.3 & 76.9 & 78.5 & 79.1 & 84.5 & 81.7 & 81.6 \\
\hline Alagoas - AL & 13,5 & 9,9 & 9,8 & 11,9 & 10,2 & 9,4 & 9,5 & 7,3 & 8,4 & 7,9 \\
\hline Bahı- BA & 0,0 & 0,5 & 0,0 & 0,5 & 0,5 & 0,1 & 0,5 & 0,1 & 0,5 & 0,8 \\
\hline Sergipe-SE & 1,0 & 0,8 & 0,6 & 0,6 & 0,6 & 0,4 & 0,3 & 0,3 & 0,3 & 0,2 \\
\hline Pernarnbucu-PE & 11,5 & 9,1 & 9,4 & 9,9 & 8,5 & 8,0 & 7,8 & 5,5 & 6,9 & 6,8 \\
\hline Paraiba-PB & 2.8 & 2.2 & 2.1 & 2.3 & 2.1 & 1.9 & 1.8 & 0.9 & 1.4 & 1.4 \\
\hline Rio Grande do Norte RN & 1,6 & 1,1 & 1,2 & 1,1 & 1,0 & 0,8 & 0,9 & 0,7 & 0,9 & 1,0 \\
\hline Maranhäo - MA & 0,3 & 0,3 & 0,3 & 0,3 & 0,3 & 0,2 & 0,1 & 0,1 & 0,1 & 0,2 \\
\hline Norte-Nordeste & 31.3 & $24 . ?$ & 240 & 2.6 .7 & 23.1 & 2.1 .5 & 20.9 & 15.5 & 18.3 & 18.4 \\
\hline
\end{tabular}

Fonte: Dados da Pesquisa. A produção de cana de cada estado foi extraída de ALCOPAR (2015a).

Primeiramente, em termos da comparação entre as macrorregiões Norte-Nordeste e Centro-Sul, nota-se a superioridade do Centro-Sul, que amplia sua participação relativa de 68,7 pontos percentuais (p.p.), do total da produção canavieira no Brasil, para 81,6 p.p., ao revés verifica-se a queda do Norte-Nordeste, de 31,3 p.p. para 18,4 p.p.

Em se tratando dos estados mais representativos neste segmento, primeiro cabe destacar que São Paulo é um outlier, porquanto sua produção foi responsável por $59 \%$ em média do total produzido no Brasil nesse período. A heterogeneidade e as oscilações existentes entre demais estados produtores de cada macrorregião 
(estes 15 selecionados responderam por $99,35 \%$ do total produzido nacionalmente) apontaram para duas perspectivas opostas: uma de crescimento da participação relativa média, ocorrência destacada para Mato Grosso, Paraná, Mato Grosso do Sul, Bahia, São Paulo e Goiás; e a outra com perda de posição relativa, em que figuram os demais estados. Sobre os três estados da região Centro-Oeste vale dizer que sua expansão esteve, conforme Meurer (2014), ancorada na política de expansão das agroindústrias canavieiras pelas fronteiras agrícolas do País, aproveitando-se principalmente do boom do Proálcool em sua fase de expansão acelerada (19801985), quando a produção de etanol hidratado aumentou quase 13 vezes. Nessa fase o IAA permitiu uma maior ampliação desse parque agroindustrial, e estados sem tradição neste segmento puderam expandir sua produção. Logo, confirma-se, com exceção do Espírito Santo, Minas Gerais e Rio de Janeiro (que oscilaram para menos), que o Centro-Sul foi de fato a macrorregião de expansão da produção canavieira, capitaneado pelos estados de São Paulo e Paraná. No Norte-Nordeste as maiores perdas de posição relativa ocorreram em Paraíba e Sergipe.

De acordo com Shikida (1997) e Shikida e Perosa (2012), sem o paradigma subvencionista e também diante da situação econômica mundial e nacional difícil, aqueles produtores que se sujeitavam a uma série de arranjos institucionais patrocinados pelo Estado, mas que não se preocupavam com melhorias em suas capacidades tecnológicas, haja vista que o modelo prevalecente de sobrevivência lhes garantia certos expedientes como margens de lucro, reserva de mercado, concessão de subsídios, etc., ao se submeterem a um regime de livre mercado, logo apresentariam debilidades econômicas e financeiras, culminando com o encerramento de suas atividades e/ou incorporação pelas unidades mais dinâmicas. Ao contrário,

[...] percebe-se que algumas empresas ligadas à agroindústria canavieira assumiram um paradigma próprio - o paradigma tecnológico -, diferenciando-se das demais empresas por meio de um maior progresso técnico. A redução nos custos de produção, através da adoção de inovações, apresentou-se como a trajetória tecnológica ideal para as empresas que se diferenciaram dentro da agroindústria canavieira. Para tanto, recorreu-se às atividades de pesquisa agronômica e industrial voltadas para o desenvolvimento setorial, enquanto as inovações tecnológicas criadas foram sendo implementadas mormente por um peculiar processo de learning-by-doing (LBD) (SHIKIDA; 1997, p.109-110).

A diminuição da produção de cana verificada em alguns estados está correlacionada com a crise das unidades produtivas. Neste sentido, de igual forma, o maior número de encerramentos de unidades produtivas foi verificado no Cen- 
tro-Sul, até porque sua representatividade numérica sempre foi maior. Com base em Olalde (1993), a partir de 1986 até a safra 1991/92, a maioria das unidades desativadas $(82,1 \%)$ correspondia a destilarias autônomas (produzem etanol), e $17,9 \%$ correspondiam a usinas com destilaria anexa (produzem açúcar e etanol), corroborando a crise do Proálcool, sendo que $28,4 \%$ estavam localizadas no Norte-Nordeste e 71,6\% no Centro-Sul. Ainda citando Olalde (1993), boa parte das empresas da agroindústria canavieira que encerraram suas atividades apresentavam baixos índices de produtividade e/ou teriam sido fruto da "corrida do álcool" empreendida por muitos empresários sem proficiência no setor. Com efeito, para Fernandes e Coelho (1996), num contexto de um regime econômico de maior liberdade de atuação, o aumento da participação no mercado das empresas mais eficientes que a média é algo natural, tornando o setor ainda mais rentável.

Em suma, a fase de desaceleração e crise do Proálcool, experimentada entre as safras 1986/1987 a 1995/1996, com ruptura do paradigma subvencionista e assimilação do paradigma tecnológico que passou a vigorar na agroindústria canavieira, marcou com um ponto de inflexão essa nova institucionalidade, ao mesmo tempo definiu a respeito da sobrevivência das unidades produtivas no setor, ou seja, serão aquelas que priorizarão o constante aperfeiçoamento de suas capacidades tecnológicas e de suas estratégias operacionais, capazes de permitirem não só o aumento da produtividade dos fatores de produção, como o desenvolvimento de novos produtos e subprodutos.

\section{2. "RECRUDESCIMENTO DA DESREGULAMENTAÇÃO, EXPLICITAÇÃO DA DEBILIDADE ESTRUTURAL E O SURGIMENTO DA DIVERSIDADE DE INTE- RESSES NA AGROINDÚSTRIA CANAVIEIRA (1996/1997 A 2002/2003)"”}

Vian (2003) inspira o título desta fase conquanto agrega e ao mesmo tempo ressalta três importantes itens experimentados pela agroindústria canavieira entre as safras 1996/1997 a 2002/2003: o recrudescimento do processo de desregulamentação setorial; a explicitação da debilidade estrutural; e a diversidade de interesses.

Nessa fase o Plano Real (1994) estava em pleno vigor e inserindo mudanças significativas na economia brasileira como, por exemplo, o próprio controle da inflação; a intensificação dos processos de abertura comercial, tecnológica e financeira; e a redefinição da participação do Estado mediante equilíbrio das contas públicas, via redução das despesas e aumento das receitas, e forte processo de privatização de empresas estatais (CASTRO, 2005; BACHA, 2007). Assim, o processo de desregulamentação continuou associado ao contexto econômico de reorganização do Estado, que contribuiu para reduzir os subsídios e financiamen- 
tos ao setor sucroalcooleiro (MORAES, 2000).

Foi nesse panorama que continuaram as medidas visando o processo de liberalização na agroindústria canavieira, sendo que o preço do etanol anidro deixou de ser tabelado em 1997, enquanto os preços da cana-de-açúcar e do etanol hidratado foram liberados em 1998 e 1999, respectivamente (ALVES, 2002). Contudo, tal "liberalização veio dar origem a diferentes estratégias dos agentes econômicos com novas estruturas competitivas, fusões e um processo de migração dos capitais para as regiões 'de fronteira para a cana"' (VIAN; BELIK, 2003, p.159).

De fato, em um ambiente onde foram se tornando prevalecentes as leis de mercado, a necessidade de redução de custos via melhoria organizacional, implantação de novas tecnologias de produção agrícola e industrial, aproveitamento de subprodutos, etc., concentrou o foco das usinas e destilarias, pois sua sobrevivência setorial passou a depender destes fatores. Aumentar a escala de produção buscando reduzir custos e ganhar eficiência também passou a ser opção estratégica de algumas empresas.

Não obstante, este cenário também evidenciou o conflito de interesses e opiniões existentes entre os diversos atores econômicos da agroindústria da cana.

De modo geral, os produtores do Norte-Nordeste, por exemplo, tinham interesse em manter expedientes da intervenção, outrora existente, principalmente mecanismos como as quotas de produção que Ihes garantia mercado cativo, enquanto a equalização de custos tinha o fito de cobrir a diferença de custos entre os produtores do Norte-Nordeste e Centro-Sul, mediante subsídio pago pelo Estado (LIMA, 1992). De acordo com Moraes (2000), no Centro-Sul havia grupos que viam com cautela a desregulamentação, e outros que a almejavam, principalmente os produtores que se consideravam tolhidos com as distorções que aconteciam, sobretudo, com os sistemas de quotas e comercialização, como aqueles agregados na Cooperativa dos Produtores de Açúcar e Álcool de São Paulo (COPERSUCAR). Por outro lado, Vian e Belik (2003) dizem que, se a excessiva intervenção do governo era considerada iníqua à agroindústria canavieira, "pode-se também afirmar que o setor ainda não está maduro o suficiente para funcionar totalmente sem qualquer tipo de intervenção do Estado".

Nessa diversidade de interesses, o fato é que houve, mormente no segundo governo Fernando Henrique Cardoso [marcado pela geração de superávits primários e esforços no sentido de uma reforma estrutural cujo objetivo era o de criar condições de recuperação do investimento e crescimento econômico (OLIVEIRA; TUROLLA, 2003)], um alinhamento da economia brasileira ao contexto institucional e regulatório desse regime de política macroeconômica. Assim que se deu o 
recrudescimento do processo de desregulamentação na agroindústria canavieira, não houve volta ao paradigma subvencionista como dos tempos de existência do IAA. Logo, as usinas e destilarias foram de certo modo "induzidas" a focar com mais propriedade a melhoria de suas capacidades tecnológicas e a maximização do retorno de seus investimentos, buscando a inovação e fazendo surgir uma nova estrutura organizacional moderna, tudo isto para serem mais competitivas e poderem sobreviver no mercado. Isto, porém, não abdicou da necessidade de coordenação dos interesses dos agentes econômicos para que o setor não pudesse experimentar, por exemplo, crises de superprodução e/ou falta de abastecimento.

Diante desse cenário, novas organizações corporatistas surgiram, é o caso da mais importante delas, a União da Indústria de Cana-de-Açúcar (UNICA), criada em 1997, sendo resultado da fusão de diversas organizações setoriais do Estado de São Paulo, com "o objetivo de unificar os produtores frente às dificuldades emergentes da liberação, e fortalecer sua representação para lidar com o processo de desregulamentação e com o novo ambiente liberado" (BARROS; MORAES, 2002, p.162). Atualmente, "as mais de 130 companhias associadas à UNICA são responsáveis por mais de 50\% do etanol e 60\% do açúcar produzidos no Brasil" (UNICA; 2015a, p.1).

Outras organizações corporatistas, como o Sindicato da Indústria do Açúcar e do Álcool no Estado de Alagoas (SINDAÇÚCAR, 2015), fundado em 1944, uma histórica entidade de defesa e representação dos produtores de cana, açúcar, etanol e energia de Alagoas; a Associação das Indústrias Sucroenergéticas de Minas Gerais, sucessora da Associação de Usineiros de Minas Gerais, fundada em 1964 (SINDICATO DA INDÚSTRIA DE FABRICAÇÃO DO ÁLCOOL NO ESTADO DE MINAS GERAIS - SIAMIG, 2015); a Associação de Produtores de Bioenergia do Estado do Paraná (ALCOPAR, 2015d), fundada em 1981, constituída pelos produtores de bioenergia do Paraná; o Sindicato da Indústria de Fabricação de Etanol do Estado de Goiás/Sindicato da Indústria de Fabricação de Açúcar do Estado de Goiás (SIFAEG/ SIFAÇÚCAR, 2015), fundado em 1984, já vinham atuando no setor com o objetivo de representar as associadas na defesa e preservação dos seus interesses gerais e comuns, colaborando e atuando na elaboração de políticas de interesse da categoria.

Já a recente organização corporatista, a Associação dos Produtores de Bioenergia do Mato Grosso do Sul (BIOSUL; 2015, p.1), criada em 2008, congregando os Sindicatos das Indústrias de Fabricantes de Álcool (SINDAL), de Açúcar (SINDAÇÚCAR) e de Geração de Energia Elétrica de Pequeno e Médio Porte (SINERGIA), que representa legalmente os produtores de cana, açúcar, etanol e energia, do Mato Grosso do Sul, coordenando ações institucionais junto a órgãos 
governamentais, "adotou um moderno sistema de representação setorial, que tem como características fundamentais a gestão profissional e participativa".

No âmbito do setor público, foi instalada a Câmara Setorial da Cadeia Produtiva do Açúcar e do Álcool, em maio de 2003, pelo Ministério da Agricultura, Pecuária e Abastecimento (MAPA), sendo definitivamente criada pela Portaria $n$. 154 , de 2/07/2004, e posteriormente alterada pela Portaria n. 12, de 5/01/2006, sendo constituída por representantes de diversos segmentos dos setores público e privado que mantêm interfaces operacionais ou que compõem a cadeia produtiva do açúcar e do etanol, objetivando debater coletivamente os problemas do setor e buscar as melhores soluções possíveis para o mesmo (GONÇALVES JÚNIOR et al., 2009; CÂMARAS SETORIAIS E TEMÁTICAS, 2015).

Ao se analisar o novo ambiente institucional vigente entre as safras 1996/1997 a 2002/2003, percebem-se outros interesses como os que compreendem:

[...] o aproveitamento de terras para a cana-de-açúcar nas regiões de fronteira agrícola, a crescente entrada do investimento direto estrangeiro (IDE) na agroindústria canavieira, a busca pela viabilidade econômica também com bases socioambientais, a perspectiva de ampliação do mercado interno e externo de açúcar e etanol (por causa do argumento de maior sustentabilidade ambiental do etanol quando comparado aos combustíveis de procedimento fósseis), a produção de energia elétrica por meio da cogeração, a mecanização da colheita (que ainda está passando por uma fase de aprendizagem) e proibição da queima da cana, o processo de concentração/centralização de capitais, a melhoria das condições de trabalho e renda dos assalariados da cana, e outros (SHIKIDA; 2014, p.13-14).

Com a intensificação da desregulamentação e o surgimento da diversidade de interesses na agroindústria canavieira, a explicitação da debilidade estrutural foi inevitável. Vian (2003) chama a atenção para o fato da competitividade deste setor estar fundamentada nos anos 1990, em grande medida, nos baixos salários, na expansão extensiva e no ainda baixo aproveitamento de subprodutos e, em se comparando as macrorregiões Norte-Nordeste (no geral, mais atrasada) e Centro-Sul (no geral, mais moderna), as diferenças são enormes, evidenciando um panorama de heterogeneidade produtiva.

A consequência dessa debilidade estrutural pode ser aferida pela: evolução da produção canavieira (com opção pela renovação imediata dos canaviais ou proceder à rotação com outras culturas); fechamento ou compra de unidades produtivas; intensificação do processo de fusões (operação societária que envolve duas ou mais empresas) e aquisições (o patrimônio de uma empresa passa a ser controlado parcialmente ou totalmente por outra); e a transferência de capitais do setor de uma 
região para outra. De acordo com Siqueira e Castro Júnior (2010) e Siqueira (2013), a agroindústria produtora de açúcar, etanol e cogeração de energia, principalmente depois da diminuição da intervenção do Estado, tem passado por este processo, bem como sinaliza para a possibilidade de mais novas aquisições e fusões com o objetivo de fomentar a produção principalmente de biocombustíveis (do etanol derivado da cana), mesmo depois da crise financeira internacional e consequente restrição do crédito ocorrida em 2008. Os obstáculos para novas aquisições e fusões são basicamente "a composição societária das empresas, muitas delas com forte tradição familiar, e outros problemas contábeis, já que poucas usinas de canade-açúcar fizeram a abertura de seu capital" (SIQUEIRA; 2013, p.95).

A exposição da evolução da produção canavieira no País, entre as safras 1996/1997 a 2002/2003, denota o curto, mas conturbado, período pelo qual passou este segmento produtivo, ao mesmo tempo em que aponta para a transferência de capitais do setor de uma região para outra, sobretudo para o Centro-Oeste, principal região de fronteira agrícola nacional.

A Tabela 3 (esta em números índices e para os estados) apresentam a evolução da produção de cana-de-açúcar no Brasil entre as safras 1996/1997 a 2002/2003, que aponta para uma taxa de crescimento média anual dessa produção de 0,07\% a.a. (mas não foi significativa), ou seja, menor do que a apresentada na fase anterior $(0,92 \%$ a.a.). Aqui cabe mencionar a quebra da safra ocorrida em 2000/2001.

Tabela 3 - Números índices relativos à produção de cana-de-açúcar em estados selecionados do Brasil, safras 1996/1997 a 2002/2003

\begin{tabular}{|c|c|c|c|c|c|c|c|}
\hline Estado & $1996 / 1997$ & $1997 / 1998$ & 1998/1999 & $1999 / 2000$ & $2000 / 2001$ & $2001 / 2002$ & $2002 / 2003$ \\
\hline São Paulo - SP & 59,5 & 59,9 & 63,5 & 63,4 & 58,0 & 60,4 & 60,6 \\
\hline Paraná - PR & 7.8 & 8.7 & 7.8 & 8.0 & 7.6 & 7.9 & 7.6 \\
\hline Mato Grosso do Sul - MS & 1,2 & 2,0 & 2,1 & 2,4 & 2,6 & 2,7 & 2,6 \\
\hline Mato Grosso - MT & 2,8 & 3,2 & 3,3 & 3,3 & 3,4 & 3,7 & 3,9 \\
\hline Goiás-GO & 2,9 & 2,7 & 2,7 & 2,3 & 2,8 & 3,0 & 3,1 \\
\hline Minas Gerais - MG & 3,5 & 4,0 & 4,3 & 4,4 & 4,2 & 4,2 & 4,5 \\
\hline Rio de Janeiro-RJ & 1,9 & 1,6 & 1,7 & 1,6 & 1,4 & 1,0 & 1,4 \\
\hline Espirito Santo-ES & 0,6 & 0,8 & 0,0 & 0,7 & 1,0 & 0,7 & 0,8 \\
\hline Centro-Sul & 80.8 & 82.4 & 86.0 & 86.2 & 80.9 & 83.6 & 84.5 \\
\hline Alagoas - AL & 8,2 & 7,8 & 5,5 & 6,3 & 9,5 & 7,9 & 7,2 \\
\hline Dahia-DA & 0,8 & 0,9 & 0,7 & 0,7 & 0,8 & 0,7 & 0,7 \\
\hline Sergipe-SE & 0,4 & 0,4 & 0,3 & 0,4 & 0,0 & 0,5 & 0,5 \\
\hline Pemambuco-PE & 7.0 & 5.6 & 5.0 & 4.3 & 5.6 & 4.9 & 4.6 \\
\hline $\begin{array}{ll}\text { Paraiba } & \text { PB }\end{array}$ & 1,7 & 1,8 & 1,2 & 1,1 & 1,1 & 1,1 & 1,1 \\
\hline Rio Grande do Norte - RN & 0,9 & 0,9 & 0,9 & 0,6 & 0,9 & 0,7 & 0,8 \\
\hline Maranhão-MA & 0,3 & 0,3 & 0,4 & 0,3 & 0,3 & 0,4 & 0,3 \\
\hline Norte-Nordeste & 19,2 & 17,6 & 14,0 & 13,8 & 19,1 & 16,4 & 15,5 \\
\hline
\end{tabular}

Fonte: Dados da Pesquisa. A produção de cana de cada estado foi extraída de ALCOPAR (2015a).

O cotejo entre as macrorregiões Norte-Nordeste e Centro-Sul, para o período compreendido entre as safras mencionadas, mostra uma ampliação do total da produção canavieira do Centro-Sul frente ao Norte-Nordeste, que saiu de 80,8 
p.p. para 84,5 p.p. Contudo, este crescimento de 3,7\% foi bem aquém do ocorrido na fase anterior, que foi de $12,9 \%$. A taxa de crescimento média anual para o Centro-Sul foi de $0,44 \%$ a.a., enquanto esta taxa para o Norte-Nordeste foi de $-1,6 \%$ a.a. (ambas, porém, não foram significativas).

Esta ampliação de uma macrorregião sobre a outra, ainda que menor, é um dos indicadores que justificam a debilidade estrutural apontada no título dessa fase, sentida com maior veemência no Norte-Nordeste, por ser esta a região menos favorecida em termos de competitividade setorial. Embora seja bom destacar, existam, segundo Shikida $(1997 ; 2014)$, casos de modernidade agroindustrial canavieira no Norte-Nordeste, da mesma forma que se verificam casos de atraso tecnológico no Centro-Sul.

Como destaques pontuais, São Paulo continuou sendo responsável por expressiva parcela (média de $60 \%$ ) do total produzido de cana-de-açúcar no âmbito nacional. Os estados que apresentaram crescimentos da participação relativa média da produção canavieira, nesta ordem, foram: Mato Grosso, Mato Grosso do Sul, Maranhão, Minas Gerais, Espírito Santo, Sergipe, Goiás e São Paulo. Repete-se a expansão da cana-de-açúcar no Centro-Oeste, principal fronteira agrícola do País. Minas Gerais e Espírito Santo (no Centro-Sul), Maranhão e Sergipe (no Norte-Nordeste), que oscilaram para menos no período anterior, agora apresentaram recuperação. As oscilações negativas foram para os seguintes estados: Paraná [neste caso muito em função da limitação espacial de terras aptas ao cultivo da canade-açúcar - Dahmer-Felício (2011), circunscritas ao Paralelo 24 e acima] e Rio de Janeiro (no Centro-Sul); e Rio Grande do Norte, Alagoas (também com restrições de expansão espacial da produção), Bahia, Paraíba e Pernambuco (no Norte-Nordeste). Ressalta-se que dois estados com tradição secular neste segmento, Alagoas e Pernambuco, assim como os demais, estão passando por transformações de sua estrutura técnico-produtiva e, embora figurem com oscilações negativas, em que seus estabelecimentos se mantiveram com sustentabilidade econômica e condições técnicas de competição, a atividade continuou a existir, diferentemente de outras áreas onde foram erradicadas (LAGES, 1993; CARVALHO, 2007).

Durante as safras 1996/1997 a 2002/2003, a taxa de crescimento média anual da produção de etanol foi de $-4,5 \%$ a.a. (significativa a $5 \%$ ), ao revés, a taxa de crescimento do açúcar no Brasil foi de 6,1\% a.a. (significativa a 5\%), confirmando a tendência da fase anterior de reversão de importância do açúcar vis-à-vis o etanol. Mercado do açúcar mais atrativo [o volume exportado de açúcar pelo Brasil cresceu 2,4 vezes mais, saindo de 5,4 milhões de toneladas em 1996 para 12,9 milhões de toneladas em 2003 (ALCOPAR, 2015a)] e incertezas sobre 
o etanol, num cenário de recrudescimento da desregulamentação, explicitação da debilidade estrutural e o surgimento da diversidade de interesses na agroindústria canavieira, justificam a maior força do açúcar nesse momento.

\section{3. "RETOMADA DO ETANOL COM O MERCADO FLEX-FUEL, IDE E FALTA DE PLANEJAMENTO (2003/2004 A 2013/2014)"}

A fase atual da agroindústria canavieira apresenta dois fatores característicos: a introdução no mercado dos automóveis flex-fuel e a retomada do consumo de etanol; e a falta de planejamento do governo federal via política de controle de preços da gasolina para tentar frear a inflação, mostrando incoerência de planejamento. Estes dois fatores serão o norte desta seção, complementada por aspectos que também a influenciaram(am).

Com efeito, para a agroindústria canavieira, o ano de 2003 foi muito importante, porque marcou o início da produção em série de veículos flex-fuel no Brasil, quando a Volkswagen começou a produzir automóveis que possibilitam tanto o uso da gasolina como de etanol ou de um mix entre ambos, dando ao consumidor o inédito poder de decisão de escolher o combustível no momento de abastecer. Bem aceito no mercado, seja pela relação preço [abastecer com etanol vale a pena se o preço do litro custar até $70 \%$ do preço do litro da gasolina, mas já há estudos que apontam para 80\% (CRAIDE, 2014)], seja pelo apelo ambiental (o etanol polui menos), em 2005 já havia veículos flex-fuel sendo produzidos também por outras montadoras como a Chevrolet, Fiat, Ford, Peugeot, Renault, Honda, Mitsubishi, Toyota e Citroën. O sucesso comercial deste tipo de veículo pode ser atribuído não somente ao esforço inovativo das montadoras, como à tradição e cultura do consumidor brasileiro como usuário do etanol, e à herança do Proálcool enquanto política estimuladora desse combustível renovável (UNICA, 2012).

Outra inovação vem surgindo no sentido de ampliar o consumo de etanol, é o que atesta CG 150 START... (2014), que realça o fato de a Honda vir realizando pesquisas para introduzir no mercado a motocicleta modelo CG 150, com possibilidade de abastecimento tanto com gasolina, etanol ou de um mix entre ambos os combustíveis. Também na área da aviação já existe o modelo Ipanema (EMB 202A), com tecnologia inédita no mundo, porquanto utiliza $100 \%$ de etanol da cana como combustível (MOVIDO A ETANOL, AVIÃO..., 2014).

A Tabela 4 expõe o extraordinário crescimento do mercado flex-fuel, no qual o crescimento da percentagem de venda deste tipo de veículo foi de $2.169 \%$ de 2003 a 2013. 
Tabela 4 - Percentagem de venda de veículos flex-fuel (álcool/gasolina) no mercado brasileiro (2003-2013)

\begin{tabular}{c|r|r|r|r|r|r|r|r|r|r|r}
\hline Anos & $\mathbf{2 0 0 3}$ & $\mathbf{2 0 0 4}$ & $\mathbf{2 0 0 5}$ & $\mathbf{2 0 0 6}$ & $\mathbf{2 0 0 7}$ & $\mathbf{2 0 0 8}$ & $\mathbf{2 0 0 9}$ & $\mathbf{2 0 1 0}$ & $\mathbf{2 0 1 1}$ & $\mathbf{2 0 1 2}$ & $\mathbf{2 0 1 3}$ \\
\hline $\begin{array}{c}\text { \% de venda de veículos flex-fuel } \\
\text { no mercado interno }\end{array}$ & 3,9 & 22,5 & 52,7 & 81,8 & 89,1 & 87,2 & 88,2 & 86,4 & 83,1 & 87,0 & 88,5 \\
\hline
\end{tabular}

Fonte: ALCOPAR (2015e); ASSOCIAÇÃO NACIONAL DOS FABRICANTES DE VEÍCULOS AUTOMOTORES (ANFAVEA) (2015).

No contexto de fortalecimento dos debates internacionais acerca das questões ambientais, a tecnologia flex ganhou relevância, é o que expõe UNICA (2012, p.1):

[...] entre março de 2003 e setembro de 2012, o abastecimento de carros flex com etanol hidratado, um combustível renovável, ou com gasolina, que atualmente contém $20 \%$ de etanol misturado, gerou uma redução pelos consumidores brasileiros de 177.238.070 toneladas de dióxido de carbono $\left(\mathrm{CO}_{2}\right)$, um dos mais perigosos gases responsáveis pelo efeito estufa (GEEs) e, como consequência, as mudanças climáticas.

O renovado interesse pelo etanol, proporcionado pela nova tecnologia flex, afetou diretamente a dinâmica da produção canavieira pós-2003. A Tabela 5 (esta em números índices e para os estados) apresentam a evolução da produção de cana no Brasil, ocorrida entre as safras 2003/2004 a 2013/2014, em que se verifica a taxa de crescimento média anual da produção de $6,4 \%$ a.a. (significativa a $1 \%$ ), sinalizando para uma recuperação considerável em relação às fases anteriores (para o período 1996/1997-2002/2003 esta taxa foi de 0,07\%, e entre 1986/19871995/1996 foi de 0,92\% a.a.). Um dos grandes alavancadores da produção canavieira foi certamente este novo ímpeto mercadológico do etanol, cuja taxa de crescimento média anual da produção foi de $6,9 \%$ a.a., significativa a $1 \%$ (para a fase anterior esta taxa foi de $-4,5 \%$ a.a.). Já a taxa de crescimento da produção de açúcar foi de 5,1\% a.a. (significativa a 1\%), quase 2 p.p. menor do que a do etanol, revertendo a tendência das fases anteriores de importância do etanol vis-à-vis o açúcar. Outro indicador de mudança de perspectiva desse mercado é apontado pelos dados da ALCOPAR (2015b), que mostra que o consumo de álcool carburante quase que dobrou na fase atual, saindo dos 11,5 milhões de $\mathrm{m}^{3} \mathrm{em} 2003$ para se situar entre os 22 milhões de $\mathrm{m}^{3}$ nas últimas safras. Mesmo assim cabe destacar que a commodity açúcar também vinha apresentando crescimento de sua produção (para 1996/1997 a 2002/2003 a taxa de crescimento do açúcar no Brasil foi de $6,1 \%$ a.a., um pouco maior do que na atual fase). De fato, o açúcar continuou tendo um cenário externo favorável, tanto que o volume exportado dessa commodity pelo Brasil mais do que dobrou, saindo de 12,9 milhões de toneladas em 2003 para 26,6 
milhões de toneladas na última safra considerada - 2013/2014 (ALCOPAR, 2015a, UNICA, 2015b). Neves (2014) corrobora esta conjuntura favorável ao citar que o consumo de açúcar no mundo tem crescido em média 2,24\% a.a.

Tabela 5 - Números índices relativos à produção de cana-de-açúcar em estados selecionados do Brasil, safras 2003/2004 a 2013/2014

\begin{tabular}{|c|c|c|c|c|c|c|c|c|c|c|c|}
\hline Estado & $03 / 04$ & $04 / 05$ & $05 / 06$ & $06 / 07$ & $07 / 08$ & $08 / 09$ & $09 / 10$ & $10 / 11$ & $11 / 12$ & $12 / 13$ & $13 / 14$ \\
\hline $\mathrm{SP}$ & 58,1 & 59,8 & 63,3 & 64,2 & 60,1 & 61,7 & 60,3 & 58,2 & 54,8 & 56,4 & 56,6 \\
\hline PR & 80 & 7.6 & 65 & 78 & 82 & 79 & 76 & 70 & 73 & 68 & 6.5 \\
\hline MS & 2,5 & 2,5 & 2,4 & 2,8 & 3,0 & 3,2 & 3,2 & 5,4 & 6,1 & 6,4 & 6,4 \\
\hline MT & 4,0 & 5,6 & 3,2 & 3,2 & 2,9 & 2,5 & 2,3 & 2,2 & 2,4 & 2,8 & 2,6 \\
\hline GO & 3,6 & 3,6 & 3,8 & 3,9 & 4,2 & 5,2 & 6,7 & 7,4 & 8,1 & 9,0 & 9,6 \\
\hline $\mathrm{MG}$ & 5,3 & 3,8 & 6,4 & 7,1 & 7,3 & 7,3 & 8,3 & 9,0 & 9,0 & 8,9 & 9,4 \\
\hline RI & 1,3 & 1,5 & 1,3 & 0,8 & 0,8 & 0,6 & 0,5 & 0,4 & 0,4 & 0,2 & 0,3 \\
\hline ES & 0,8 & 1,0 & 1,0 & 0,7 & 0,8 & 0,8 & 0,1 & 0,0 & 0,8 & 0,0 & 0,6 \\
\hline Centro-Sul & 83.5 & 85.4 & 87.8 & 90.6 & 87.3 & 89.1 & 90.3 & 90.2 & 88.8 & 91.1 & 92.0 \\
\hline$\Lambda L$ & 8,0 & 6,8 & 5,8 & 1,1 & 6,0 & 1,8 & 1,0 & 1,7 & 5,0 & 1,0 & 3,3 \\
\hline $\mathrm{BA}$ & 0,6 & 0,6 & 0,6 & 0,5 & 0,5 & 0,4 & 0,3 & 0,4 & 0,5 & 0,5 & 0,5 \\
\hline $\mathrm{SE}$ & 0,4 & 0,4 & 0,3 & 0,2 & 0,3 & 0,3 & 0,2 & 0,3 & 0,5 & 0,4 & 0,4 \\
\hline PE & 4,9 & 4,3 & 3,6 & 2,7 & 4,0 & 3,3 & 3,0 & 2,7 & 3,2 & 2,3 & 2,3 \\
\hline PD & 1,4 & 1,4 & 1,1 & 0,7 & 1,1 & 1,0 & 1,0 & 0,8 & 1,2 & 0,9 & 0,8 \\
\hline $\mathrm{KN}$ & 0,1 & 0,8 & 0,0 & 0,4 & 0,4 & 0,0 & 0,6 & 0,4 & 0,5 & 0,4 & 0,3 \\
\hline MA & 0.4 & 0.3 & 0.2 & 0.3 & 0.4 & 0.4 & 0.4 & 0.4 & 0.4 & 0.4 & 0.3 \\
\hline Norte Nordeste & 16,5 & 11,6 & 12,2 & 9,1 & 12,7 & 10,9 & 9,7 & 9,8 & 11,2 & 8,9 & 8,0 \\
\hline
\end{tabular}

Fonte: Dados da Pesquisa. A produção de cana de cada estado foi extraída de ALCOPAR (2015a) e UNICA (2015b).

A comparação entre as macrorregiões Norte-Nordeste e Centro-Sul, para o período 2003/2004 a 2013/2014, mostra a continuidade da ampliação do total da produção canavieira do Centro-Sul frente ao Norte-Nordeste, que saiu de 83,5 p.p. para 92 p.p. Este crescimento de 8,5 p.p. foi maior do que o evidenciado na fase anterior (3,7\%), mas aquém do ocorrido na fase 1996/1997-2002/2003, que foi de $12,9 \%$. A taxa de crescimento média anual da produção canavieira para o Centro-Sul foi de $7,1 \%$ a.a. (significativa a $1 \%$ ), enquanto esta taxa para o NorteNordeste foi de $0,7 \%$ a.a. (não significativa). Observa-se que, desta vez, a produção canavieira do Centro-Sul foi, em média, oito vezes maior do que a produção do Norte-Nordeste, com tendência de ampliação deste escore. Nas fases anteriores esta relação foi de quatro e cinco vezes mais, respectivamente.

Como destaques pontuais da Tabela 5, São Paulo continuou sendo responsável por expressiva parcela do total produzido de cana-de-açúcar no âmbito nacional, média de quase $60 \%$, mas com tendência de diminuição de sua posição relativa. Os estados que apresentaram crescimentos de participação relativa da produção canavieira, com ampliações consideráveis, foram Goiás e Mato Grosso do Sul. Minas Gerais também obteve aumento de sua participação, mas ficou um pouco distante dos dois estados centro-oestinos citados. Com exceção de Sergipe, que praticamente se manteve, em termos dessa participação, todos os demais 
estados perderam posição relativa, sendo as maiores perdas para os estados de Pernambuco, Rio Grande do Norte, Alagoas e Rio de Janeiro. Novamente corroborou-se a expansão da cana-de-açúcar no Centro-Oeste, mas apenas para dois estados, pois o Mato Grosso perdeu posição relativa. Também se evidenciou que, agora, não houve exceções para o cenário norte-nordestino, pois não ocorreram aumentos de suas participações relativas para nenhum estado.

Sobre esta diferença, em termos de Centro-Oeste, Meurer (2014) coloca que os dois estados mais próximos ao mercado centro-sulista, Goiás e Mato Grosso do Sul, não por acaso área de "transbordamento" (quando a produção de uma determinada área chega ao seu limite, avançando para outras) da hegemônica agroindústria canavieira de São Paulo, são os mais beneficiados em termos de expansão da cana em função de suas localizações geográficas e por apresentarem terras férteis ainda não utilizadas ou usadas pela pecuária extensiva, facilmente mecanizáveis, com condições climatológicas apropriadas, onde a cultura da cana apresenta perspectiva de elevada produtividade. O Mato Grosso também tem condições naturais semelhantes, porém é mais distante geograficamente do mercado centro-sulista e ainda apresenta mais restrições em termos do que foi estabelecido pelo Zoneamento Agroecológico da Cana-de-Açúcar (ZAE Cana), que sinaliza que os estados que apresentam as maiores áreas aptas para a expansão da cultura canavieira são Goiás (12,6 mil hectares), Minas Gerais (11,3 mil hectares) e Mato Grosso do Sul (10,9 mil hectares).

Sobre a perda de importância relativa do Norte-Nordeste, um importante ponto deve ser mencionado, qual seja, tradicionais grupos canavieiros nordestinos, especialmente alagoanos, expandiram fração do seu capital agroindustrial para o Centro-Sul. Isto evidentemente está ligado com a intenção de estabelecer produção mais próxima do mercado consumidor centro-sulista e das novas tecnologias (CARVALHO, 2009). Conforme Vian et al. (2008, p.530), com a desregulamentação, as usinas e destilarias no Brasil passaram por uma profunda transformação na sua dinâmica competitiva, e quem se modernizou pode avançar, possibilitando algo nunca visto antes, "a migração de grupos nordestinos para o Centro-Sul".

Uma observação que deve ser realçada diz respeito à queda da produção entre as safras 2010/2011 e 2011/2012, creditada a problemas climáticos e aos efeitos decorrentes da crise financeira internacional de 2008, que reduziu substancialmente os créditos para muitas atividades produtivas, e a agroindústria canavieira não foi exceção. Ademais, esta conjuntura pegou algumas unidades com uma herança de 
alto endividamento, concomitante com reduzida capacidade de pagamento. Com a conjugação desses três fatores (problemas climáticos, recursos financeiros escassos e dívidas), manter e renovar o canavial, bem como produzir etanol e/ou açúcar se tornou muito custoso, culminando, amiúde, com o encerramento das atividades ou mesmo vendas de empresas. De acordo com EM SP, CRISE NAS USINAS... (2015, p.1) "nos últimos quatro anos, 44 usinas fecharam as portas no Brasil, 24 só no Estado de São Paulo, sendo cinco na região de Sertãozinho".

Relacionado com esta crise conjuntural, existe um problema que atingiu seriamente o segmento alcooleiro, num momento em que os carros flex dominam o mercado. Segundo Moreira (2014) e Freitas (2014), o fato de o governo federal, via Petrobras, ter passado a vender combustíveis no Brasil a um preço mais baixo do que paga no mercado internacional, evitando que a inflação internamente atingisse patamares maiores, provocou a perda da competividade do etanol. Destarte, esta estratégia contribuiu diretamente para desestimular o consumo de etanol e favorecer o consumo de derivados de petróleo (especialmente da gasolina), que passou a ficar pouco atrativo para o consumidor, mesmo com o aporte de modernas tecnologias que foram e estão sendo empregadas na produção alcooleira. Isto, sem contar que, após a descoberta do pré-sal, os combustíveis derivados do petróleo voltaram a ganhar notoriedade, contribuindo para relegar a um plano secundário o etanol.

Esta falta de coordenação e planejamento setorial tem se tornado reclame geral das organizações corporatistas que trabalham com a agroindústria canavieira (NEVES, 2014), sendo considerada uma política incoerente para com uma atividade econômica que representa um papel de importância para a questão de segurança alimentar e energética do Brasil.

Embora este cenário pontual seja considerado de retrocesso, na outra perspectiva, a de avanços, deve ser ressaltado, nesta nova fase de expansão canavieira no Brasil, o forte aporte de investimento direto estrangeiro, em função da perspectiva de crescimento da demanda mundial por biocombustíveis, açúcar e energia (que obviamente têm suas oscilações, mas que apresentam mercados potenciais), e diante das oportunidades abertas pela desregulamentação setorial iniciada nos anos 1990 (CARDOSO et al., 2009). Igualmente, as fusões e aquisições, enquanto estratégias tomadas pelas empresas que buscam racionalizar a produção, melhorando os processos de gestão e transferência de capacitações, e também espelho da situação das usinas e destilarias que se encontravam em situação de insolvência, tiveram campo fértil de 2004 em diante. Vale citar que Siqueira (2013) fez uma importante compilação das principais transações ocorridas 
no setor sucroalcooleiro de 2004 a 2012 (compra/aquisição/fusão...).

Com o forte aporte de investimento direto estrangeiro, bem como ampliação do número de fusões e aquisições, a agroindústria canavieira brasileira mudou seu perfil, inclusive merecendo "retificações", quando for o caso, do termo "brasileira". Isto porque, de acordo com Oliveira (2013), este setor atingiu uma marca impressionante de 33\% da produção brasileira de açúcar e álcool ser de bandeira estrangeira, sobretudo americana, francesa, inglesa, japonesa, chinesa e indiana.

O capital estrangeiro é bem vindo por trazer crédito e investir na modernização industrial e na renovação dos canaviais, sendo que suas modificações estruturais implicam não só a busca por maior mercado, como avanços em termos de modernização tecnológica do processo produtivo. O capital internacional apregoa isto (SHIKIDA, 2014). Não obstante, diante dessa expansão desenfreada (em 2006 a participação do capital estrangeiro era de apenas 3\%, em 2010 já havia subido para $12 \%$ e agora atingiu $33 \%$ ), corre-se o risco de perda da soberania nacional no estabelecimento da política agrícola correlata com este segmento. Um adendo deve ser realçado; as empresas internacionais estão comprando as unidades (usinas e/ou destilarias), porém, a compra de terras, de acordo com a Advocacia Geral da União (AGU), limita-se em cinco mil hectares o volume de terras em mãos de estrangeiros (OLIVEIRA, 2013).

Freitas et al. (2014, p.9) cita que, em um segmento que "se caracterizava pela relativa desconcentração e/ou pulverização, ou seja, o controle dos estabelecimentos de produção de açúcar e álcool estava vinculado a famílias tradicionais ligadas ao setor", agora mostra a pujança de cinco grandes grupos sucroalcooleiros dominando 43\% da moagem de cana-de-açúcar, cujo capital já não tem mais pátria.

Por último, mas não menos importante, o período 2003/2004 a 2013/2014 também evidenciou, sob a égide da desregulamentação, o vigor do paradigma tecnológico, em que os produtores, posto o ambiente mais concorrencial, estão procurando adaptar novas e producentes variedades de cana, avançando também em termos de técnicas agrícolas, industriais e de colheita (fertirrigação, colheita mecanizada, etc.), tudo visando maior competitividade. Pelo relatado neste artigo, quem não focou isto, ou teve sua unidade vendida ou encerrou suas atividades.

Embora com problemas climáticos que atingiram especialmente o ano de 2011 (o que afetou com mais intensidade a safra 2011/2012), um indicador que corrobora esta preocupação é a evolução da produtividade agrícola da cana-de-açúcar. Dados da Companhia Nacional de Abastecimento - CONAB (2015) mostram que a média da produtividade agrícola da cana no Brasil das safras 2005/2006 a 
2009/2010 foi de 79 t/ha, caindo para 72 t/ha para 2010/2011 e 2011/2012, e praticamente se mantendo nesta monta em 2012/2013 e 2013/2014, mas com tendência de recuperação a partir de 2011/2012. Outro aspecto apontado, entre as safras 2005/2006 a 2013/2014, é a produtividade média da macrorregião Centro-Sul (79,5 t/ha) ser em média 1,4 vezes maior do que a do Norte-Nordeste (56,6 t/ha).

Analisando o período 2000 a 2010, Siqueira (2013) calcula, com base nos dados do Instituto Brasileiro de Geografia e Estatística (IBGE), a taxa média de crescimento anual da produtividade agrícola da cana para o Brasil, que foi de 1,35\% a.a. (com uma média de 74,7 t/ha). Em termos dos principais estados produtores, as maiores médias dessa produtividade agrícola foram nesta ordem: São Paulo (82 t/ha), Goiás (80 t/ha), Paraná (79,8 t/ha), Mato Grosso do Sul (76,7 t/ ha), Minas Gerais (73,7 t/ha), Mato Grosso (68,4 t/ha), Alagoas (61,7 t/ha) e Pernambuco (52,7 t/ha). No entanto, em termos de maiores taxas de crescimento da produtividade agrícola da cana, os destaques (com resultados significativos em termos do teste $t$ ) foram: Minas Gerais (2,53\% a.a.), Mato Grosso do Sul (1,86\% a.a.), Pernambuco (1,39\% a.a.), São Paulo ( $0,90 \%$ a.a.) e Goiás ( $0,65 \%$ a.a.). Paraná. Alagoas e Mato Grosso apresentaram resultados não significativos.

\section{CONSIDERAÇÕES FINAIS}

A evolução da agroindústria canavieira no Brasil foi, de certo modo, moldada não somente pela abundância de recursos naturais, advinda de antigas e novas áreas de produção, mas também por uma grande quantidade de variáveis e ocorrências que condicionaram os períodos ora descritos. Em suma, a mudança do paradigma subvencionista para o paradigma tecnológico consistiu num marco para a agroindústria canavieira ao propiciar, entre outros, o fortalecimento de um capital humano especializado em decorrência de investimentos em infraestrutura de pesquisa e desenvolvimento, com implicações importantes no aprendizado de novas técnicas para criar e depois extrair valor dos canaviais, que tinham pouco ou nenhum valor durante período de intervenção estatal. Isto motivado pelo ambiente de maior concorrência pós-desregulamentação setorial.

Como corolário, embora a dotação de recursos naturais da economia continue sendo uma fonte importante de vantagens comparativas, de acordo com Mowery e Rosenberg (2005), outras características desta atividade, assim como seu grande mercado interno (mormente para o etanol), continuam a oferecer vantagens competitivas em produtos e tecnologias específicas. 
Por fim, este artigo procurou fazer uma análise histórica de um importante período da evolução da agroindústria canavieira à guisa da literatura, novos avanços neste sentido certamente engrandecerão o debate.

\section{REFERÊNCIAS}

Agrianual 96. (1996) Anuário estatístico da agricultura brasileira. São Paulo, 392 p. Alves, L. R. A. (2002) Transmissão de preços entre produtos do setor sucroalcooleiro do Estado de São Paulo. Piracicaba, 107 p. Dissertação. Escola Superior de Agricultura "Luiz de Queiroz", Universidade de São Paulo.

Associação De Produtores De Bioenergia Do Estado Do Paraná - Alcopar. (2015a) Estatísticas Brasil. Disponível em: <http://www.alcopar.org.br/estatisticas>. Acesso em 08 jan. 2015.

Associação De Produtores De Bioenergia Do Estado Do Paraná - Alcopar. (2015b) Consumo aparente de álcool carburante. Disponível em: <http://www.alcopar.org.br/estatisticas/consalcool.htm>. Acesso em 17 jan. 2015.

Associação De Produtores De Bioenergia Do Estado Do Paraná - Alcopar. (2015c) Porcentagem de venda de autoveículos a álcool no mercado interno. Disponível em: <http://www.alcopar.org.br/estatisticas/porcven_alcool.htm>. Acesso em 17 jan. 2015.

Associação De Produtores De Bioenergia Do Estado Do Paraná - Alcopar. (2015d) Histórico da Alcopar. Disponível em: <http://www.alcopar.org.br/institucional/ hist_alcopar.php>. Acesso em 17 jan. 2015.

Associação De Produtores De Bioenergia Do Estado Do Paraná - Alcopar. (2015e) Porcentagem de venda de autoveículos flex-fuel (álcool/gasolina) no mercado interno. Disponível em: <http://www.alcopar.org.br/estatisticas/porcven_ flex.htm>. Acesso em 08 jan. 2015.

Associação Dos Produtores De Bioenergia Do Mato Grosso Do Sul - Biosul. (2015) Quem somos. Disponível em <http://www.biosulms.com.br/institucional/quem-somos.html>. Acesso em 09 jan. 2015.

Associação Nacional Dos Fabricantes De Veículos Automotores - Anfavea. (2015) Carta da ANFAVEA. Disponível em: <http://www.anfavea.com.br/cartas/carta332.pdf>. Acesso em 23 jan. 2015.

Bacha, C. J. C. (2007) Entendendo a economia brasileira. Campinas: Alínea, 108 p.

Barros, G. S. A. De C.; Moraes, M. A. F. De. (2002) A desregulamentação do setor sucroalcooleiro. Revista de Economia Política, v. 22, n. 2 (86), p. 156-173. 
Câmaras Setoriais e Temáticas. (2015) Açúcar e Álcool. Disponível em: <http:// www.agricultura.gov.br/camaras-setoriais-e-tematicas>. Acesso em 20 jan. 2015.

Cardoso, R. D.; Rodrigues, K. F.; Dahmer, V. De S.; Shikida, P. F. A. (2009) Índice de desenvolvimento do setor externo sucroalcooleiro brasileiro: uma análise de 1999 a 2007. Revista de Economia e Agronegócio, Viçosa (MG), v. 7, n. 3, p. 337-361.

Carneiro, D. D.; Modiano, E. (1992) Ajuste externo e desequilíbrio interno: 1980 1984. In: Abreu, M. De P. (Org.). A ordem do progresso: cem anos de política econômica republicana, 1889-1989. Rio de Janeiro: Campus, p. 323-346.

Carvalho, C. P. De O. (2009) Análise da reestrutura produtiva da agroindústria sucroalcooleira alagoana. 3 ed. Maceió: Edufal, 86 p.

Carvalho, C. P. De O. (2007) Setor sucroalcooleiro: a ultra-especialização como estratégia competitiva (1990/2008). Economia e Desenvolvimento, Recife, v. 6, n. 2, p. 259-286.

Castro, L. B. (2005) Privatização, abertura e desindexação: a primeira metade dos anos 90 (1990-1994). In: Giambiagi, F.; Villela, A.; Castro, L. B.; Herman, J. (Orgs.). Economia brasileira contemporânea. Rio de Janeiro: Campus, p. 141-165.

Cg 150 Start: (2014) Lançamento Honda Que Vai Agitar O Mercado. Disponível em: <http://www.gruposolucao.net/honda2w/index.php?cod_secao=noticia18>. Acesso em 10 jan. 2015.

Companhia Nacional De Abastecimento - Conab. (2015) Séries Históricas. Disponível em: <http://www.conab.gov.br/conteudos.php?a=1252\&\&Pagina_objcmsconteudos=2\#A_objcmsconteudos>. Acesso em 09 jan. 2015.

Craide, S. (2014) Empresa diz que etanol é vantajoso se custar até $80 \%$ do preço da gasolina. Disponível em: <http://agenciabrasil.ebc.com.br/geral/noticia/2014-03/empresa-diz-que-etanol-e-vantajoso-se-custa-ate-80-do-preco-da-gasolina>. Acesso em 05 jan. 2015.

Dahmer-Felício, V. S. (2011) Avaliação de contratos na agroindústria canavieira paranaense utilizando a Nova Economia Institucional e Análise Fatorial de Correspondência. Toledo, 95 p. Dissertação. Programa de Pós-Graduação em Desenvolvimento Regional e Agronegócio, UNIOESTE.

Em Sp, Crise Nas Usinas De Cana Fecha Centenas De Postos De Trabalho. (2015) Disponível em: <http://www.udop.com.br/index.php?item=noticias\&cod=1116586> . Acesso em 17 jan. 2015.

Fernandes, E. S. L.; Coelho, S. T. (1996) (Orgs.) Perspectivas do álcool combus- 
tível no Brasil. São Paulo: USP-IEE, 166 p.

Freitas, E. P. De; Rossini, R. E.; Queirós, M. (2014) O poder das empresas transnacionais sobre o território brasileiro. reflexões a partir do sector sucroenergético. In: XIII COLÓQUIO INTERNACIONAL DE GEOCRÍTICA, 13., Barcelona. Anais... Barcelona: UNIVERSITAT BARCELONA, 2014. Disponível em: <http://www.ub.edu/geocrit/coloquio2014/Elisa\%20Pinheiro\%20de\%20 Freitas.pdf>. Acesso em 13 jan. 2015.

Freitas, T. Subsídio à gasolina prejudica etanol e Petrobras, diz especialista. 2014. Disponível em: <http://www.udop.com.br/index.php?item=noticias\&$\operatorname{cod}=1111568>$. Acesso em 13 jan. 2015.

Goldin, I.; Rezende, G. C. (1993) A agricultura brasileira na década de 80: crescimento numa economia em crise. Rio de Janeiro: IPEA,119 p.

Gonçalves Júnior, C. A.; Alves, Y. B.; Shikida, P. F. A.; Staduto, J. A. R.; Rocha Júnior, W. F. Da. (2009) Um estudo das deliberações da câmara setorial do açúcar e do álcool usando análise de correspondência. Revista de Economia e Sociologia Rural, Brasília, v. 47, n. 1, p. 183-210.

Hoffmann, R.; Vieira. S. (1987) Análise de regressão: uma introdução à econometria. 2. ed. São Paulo: HUCITEC.

Lacerda, A. C. De; Bocchi, J. I.; Rego, J. M.; Borges, M. A.; Marques, R. M. (2000) Economia brasileira. São Paulo: Saraiva.

Lages, A. M. G. (1993) A diferenciação tecnológica na indústria sucro-alcooleira do Brasil. Recife. 199 p. Dissertação. Departamento de Economia, Universidade Federal de Pernambuco.

Lima, J. C. De S. (1992) A intervenção governamental no setor açucareiro: ênfase à problemática do subsídio de equalização. São Paulo, 118 p. Tese. Doutorado em Economia. Faculdade de Economia, Administração e Contabilidade, Universidade de São Paulo.

Lopes, L. A. (1996) Vinte anos de Proálcool: avaliações e perspectivas. Economia e Empresa, v. 3, n. 2, p. 49-57.

Manzatto, C. V.; Assad, E. F.; Bacca, J. F. M.; Zaroni, M. J.; Pereira, S. E. M. (2009) Zoneamento agroecológico da cana-de-açúcar. Rio de Janeiro: Embrapa Solos.

Martins, H. H. (2015) Análise da evolução das indústrias do açúcar e do álcool no Brasil a partir da matriz insumo-produto (2000 e 2009). Toledo, 112 p. Dissertação. Programa de Pós-Graduação em Desenvolvimento Regional e Agronegócio, UNIOESTE.

Meurer, A. P. S. (2014) Análise da agroindústria canavieira nos estados do Centro 
- Oeste do Brasil a partir da matriz de capacidades tecnológicas. Toledo, 81

p. Dissertação. Programa de Pós-Graduação em Desenvolvimento Regional e Agronegócio, UNIOESTE.

Moraes, M. A. F. D. de. (2000) A desregulamentação do setor sucroalcooleiro do Brasil. Americana: Caminho Editorial, 238 p.

Moraes, M. A. F. D. de.; Shikida, P. F. A. (Orgs.). (2002) Agroindústria canavieira no Brasil: evolução, desenvolvimento e desafios. São Paulo: Atlas, 368 p.

Moreira, A. (2014) Etanol no Brasil é vítima do controle de preço da gasolina, diz AIE. Disponível em: <http://www.udop.com.br/index.php?item=noticias\&$\operatorname{cod}=1114790>$. Acesso em 18 jan. 2015.

Movido A Etanol, Avião Agrícola Ipanema Completa 10 Anos. (2014). Disponível em: <http://www.biocana.com.br/index.php/noticia/visualizar/movido-a-etanol-aviao-agricola-ipanema-completa-10-anos->. Acesso em 23 jan. 2015.

Mowery, D. C.; Rosenberg, N. (2005) Trajetórias da inovação: a mudança tecnológica nos Estados Unidos da América no século XX. Campinas: Editora da UNICAMP, $230 \mathrm{p}$.

Nardy, V.; Gurgel, A. C. (2013) Impactos da liberalização do comércio de etanol entre Brasil e Estados Unidos sobre o uso da terra e emissões de $\mathrm{CO}_{2}$. Nova Economia, Belo Horizonte, v. 23, p. 693-726.

Neves, M. F. (2014) A crise fabricada da cana. Disponível em: <http://www.jornalparana.com.br/_setadmin/uploads/4f6ce4ccfe4c8862f96903d32712da1b. pdf>. Acesso em 13 jan. 2015.

Olalde, A. R. (1993) Desenvolvimento tecnológico e competitividade da indústria brasileira: a indústria sucro-alcooleira. Campinas: SCTDE/FECAMP/UNICAMP-IE (Relatório Final).

Oliveira, G. (2013) Estrangeiros são a nova geração de usineiros. Disponível em $<$ http://oglobo.globo.com/economia/estrangeiros-sao-nova-geracao-de-usineiros-8232513>. Acesso em 18 jan. 2015.

Oliveira, G.; Turolla, F. (2003) Política econômica do segundo governo FHC: mudança em condições adversas. Tempo social. v. 15, n. 2, p.195-217.

Parro, J. E. (1996) A visão do setor automobilístico. In: Fernandes, E. S. L.; CoeIho, S. T. (Orgs.). Perspectivas do álcool combustível no Brasil. São Paulo: USP-IEE.

Paulillo, L. F.; Vian, C. E. De F.; Shikida, P. F. A.; Mello, F. T. de. (2007) Álcool combustível e biodiesel no Brasil: quo vadis? Revista de Economia e Sociologia 
Rural, Brasília, v. 45, n. 3, p. 531-565.

Quadros, S. (1995) Ajuste necessário. Agroanalysis, v. 15, n. 3, p. 21-22.

Shikida, P. F. A. (1997) A evolução diferenciada da agroindústria canavieira no Brasil de 1975 a 1995. Piracicaba, 191 p. Tese. Escola Superior de Agricultura "Luiz de Queiroz", Universidade de São Paulo.

Shikida, P. F. A. (2014) Evolução e fases da agroindústria canavieira no Brasil. Revista de Política Agrícola, Brasília, ano XXIII, n.4, p.43-57.

Shikida, P. F. A.; Perosa, B. B. (2012) Álcool combustível no Brasil e path dependence. Revista de Economia e Sociologia Rural, Piracicaba, v.50, n.2, p.243-262.

Sindicato Da Indústria De Fabricação De Etanol Do Estado De Goiás (Sifaeg)/ Sindicato Da Indústria De Fabricação De Açúcar Do Estado De Goiás (Sifaçúcar). (2015) Quem somos. Disponível em <http://www.sifaeg.com.br/ quems_somos/>. Acesso em 09 jan. 2015.

Sindicato Da Indústria De Fabricação Do Álcool No Estado De Minas Gerais (Siamig). (2015) Quem Somos. Disponível em <http://www.siamig.org.br/index.php?option=com_content\&task=view\&id=23\&ltemid=65>. Acesso em 09 jan. 2015.

Sindicato Da Indústria Do Açúcar E Do Álcool No Estado De Alagoas (Sindaçúcar-Al). (2015) Histórico. Disponível em <http://www.sindacucar-al.com.br/ sindacucar/historico/>. Acesso em 09 jan. 2015.

Siqueira, P. H. De L. (2013) Estratégias de crescimento e de localização da agroindústria canavieira brasileira e suas externalidades. 189 p. Tese. Doutorado em Dinâmica e Gestão de Cadeias Produtivas, Universidade Federal de Lavras.

Siqueira, P. H. De L.; Castro Junior, L. L. (2010) Fusões e aquisições das unidades produtivas e da agroindústria de cana-de-açúcar no Brasil e nas distribuidoras de álcool hidratado etílico. Revista de Economia e Sociologia Rural, v. 48, n. 4, p. 709-735.

União Da Indústria De Cana-De-Açúcar (Unica). (2012) Dez anos do carro flex, etanol celulósico e o futuro do setor: destaques da edição 2013 do Ethanol Summit. Disponível em <http://www.unica.com.br/noticia/18631428920322101782/dez-anos-do-carro-flex-por-cento2C-etanol-celulosico-e-o-futuro-do-setor-por-cento3A-destaques-da-edicao-2013-do-ethanol-summit/>. Acesso em 09 jan. 2015.

União Da Indústria De Cana-De-Açúcar (Unica). (2015a) Histórico e missão. Disponível em <http://www.unica.com.br/historico-e-missao/>. Acesso em 02 jan. 2015.

União Da Indústria De Cana-De-Açúcar (Unica). (2015b) Unicadata. Disponível em <http://www.unicadata.com.br>. Acesso em 09 jan. 2015. 
Vian, C. E. De F. (2003) Agroindústria canavieira: estratégias competitivas e modernização. Campinas: Editora Átomo.

Vian, C. E. De F.; Belik, W. (2003) Os desafios para a reestruturação do complexo agroindustrial canavieiro do Centro-Sul. Economia. Niterói (RJ), v. 4, n. 1, p. 153-194.

Vian, C. E. De F.; Lima, A. A. De; Lima, R. A. de S. (2008) Estudo de impacto econômico para o setor agroindustrial canavieiro paulista e alagoano: conjuntura e agenda de pesquisa. Revista Econômica do Nordeste, Fortaleza, v. 39 , n. 4 , p. $518-539$. 